Int. J. Dev. Biol. 55: 25-31 (2011)

doi: $10.1387 / \mathrm{ijdb} .092990 \mathrm{tk}$

\title{
Antagonistic role of XESR1 and XESR5 in mesoderm formation in Xenopus laevis
}

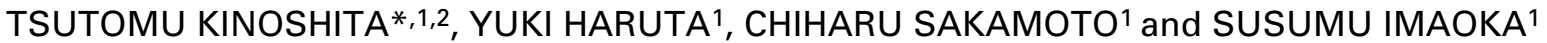 \\ ${ }^{1}$ Department of Bioscience, School of Science and Technology, Kwansei Gakuin University, Hyogo and \\ ${ }^{2}$ Department of Life Science, Faculty of Science, Rikkyo University, Tokyo, Japan
}

\begin{abstract}
The notch signaling pathway is widely conserved from vertebrates to invertebrates and mediates the specification of numerous cell fates during developmental processes. In the Xenopus gastrula embryo, Xdelta1, one of the Notch ligands, is expressed in the prospective mesoderm prior to Xbra expression. Here, we examined the role of Notch signaling in mesoderm formation. Embryos injected with Xdelta1 morpholino oligo DNA showed a severe gastrulation defect and suppression of Xbra expression, which were completely rescued by co-injection with the active form of Notch. In order to fully understand the role of Notch signaling, we examined the expression of the Notch target genes XESR1 and XESR5. RT-PCR and whole-mount in situ hybridization analyses showed that XESR5 was highly expressed in the marginal zone of the early gastrula embryo, whereas expression of XESR1 was not detected. Animal cap assays indicated that expression of XESR5 was not induced by Notch signaling but by nodal signaling. To clarify the role of XESR5 in the gastrula embryo, a dominant negative form of XESR5 was injected into the prospective mesoderm. The truncated form of XESR5 induced the ectopic expression of XESR1, which caused a decrease in Xbra expression and defective gastrulation. In contrast, the truncated form of XESR1 caused an upregulation of XESR5 resulting in an increase in Xbra expression. The antagonistic effect of XESR1 and XESR5 suggests a dual regulation in which XESR 5 produces a competent area for mesoderm formation by suppressing the gene expression of XESR1, while XESR1 sharpens the boundary of Xbra expression.
\end{abstract}

KEY WORDS: XESR1, XESR5, Xenopus, mesoderm formation

\section{Introduction}

Notch signaling plays a fundamental role during developmental processes in multicellular animals (Artavanis-Tsakonas et al., 1999; Mumm and Kopan, 2000). It mediates communication between adjacent cells and determines the cell fate at the branch point of neuron or glial cell (Hojo et al., 2000), T cell or B cell (Han et al., 2002), and endocrine or exocrine cell (Apelqvist et al., 1999). The Notch receptor is a single transmembrane spanning protein that receives signals from cell-bound ligands of the Delta or Serrate and thus functions by direct cell-cell contact. The Notch receptor undergoes a complex series of proteolytic processing events that lead to the release of the Notch intracellular domain (NICD) (Ebinu and Yankner, 2002). Presenilins are important for the final proteolytic cleavage liberating the NICD (Berezovska et al., 2000; Karlstrom et al., 2002). The cleaved NICD fragment translocates to the nucleus, where it interacts with the DNA- binding CSL protein (CBF1, Suppressor of Hairless, Lag1 family) to regulate the transcription of target genes (Furukawa et al., 1992; Jarriault et al., 1995). The key downstream genes are the HES family genes encoding basic helix-loop-helix transcription regulators (Iso et al., 2001; Jarriault et al., 1995; Maier and Gessler, 2000; Nakagawa et al., 2000).

In Xenopus embryo, the molecular mechanism of Notch signaling is well conserved, and a detailed investigation has been performed in neurogenesis (Chitnis et al., 1995; Wettstein et al., 1997; Koyano-Nakagawa et al., 1999; Kiyota et al., 2001). Prior to the neurula stage, the first zygotic expression of Xdelta1 occurs in the marginal zone of gastrula embryo (Wittenberger et al.,

\footnotetext{
Abbreviations used in this paper: AP, alkaline phosphatase; DIG, digoxigenin; DN, dominant negative form; MBS, modified Barth saline; MO, morpholino antisense oligonucleotides; NICD, notch intracellular domain.
}

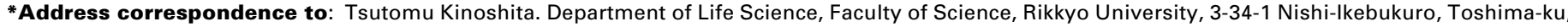
Tokyo 171-8501, Japan. Fax: +81-3-3985-3386. e-mail: tkinoshita@rikkyo.ac.jp
} 
1999). An in vitro study using animal cap assay has shown that Notch signaling in the marginal zone of gastrula embryo controls cell competence for mesoderm formation (Abe et al., 2005). However, the molecular mechanism by which Notch signaling controls mesodermal competence remains unknown. We have reported that the depletion of $\mathrm{XSu}(\mathrm{H}) 2$, which functions as a transcription factor under Notch signaling, causes the gastrulation defect (Ito et al., 2007a), suggesting that Notch signaling is required for normal gastrulation. However, the gastrulation defect caused by the depletion of $\mathrm{XSu}(\mathrm{H}) 2$ could not be rescued by one of the Notch target gene, Xenopus Enhancer of Split related gene 1 (XESR1) (Ito et al., 2007b). Here, we examine the effects of another Notch target gene, XESR5, which has been reported in segmentation of the paraxial mesoderm (Jen et al., 1999). RTPCR and whole-mount in situ hybridization showed that XESR5, but not XESR1, is expressed in the marginal zone of the early gastrula embryo. Animal cap assay indicated that gene expression of XESR5 in the marginal zone is induced not by Notch signaling but by nodal signaling. Loss- and gain-of-function experiments demonstrated that XESR1 and XESR5 antagonistically regulate the gene expression of each other. On the basis of these results, we propose a dual regulation model in which XESR5 produces a competent area for mesoderm formation by suppressing the gene expression of XESR1, while XESR1 refines the boundary of Xbra expression by suppressing the overexpression of Xbra.

\section{Results}

\section{Effect of Notch signaling on mesoderm formation}

It is well established that Xdelta1 is expressed in the marginal zone of the early gastrula embryo (Wittenberger et al., 1999). To compare the spatiotemporal expression between Xbra and Xdelta1, whole-mount in situ hybridization was performed on the early gastrula. Gene expression of Xbra was not detected in the early gastrula embryo, while broad expression of Xdelta1 was observed in the animal hemisphere of st.9 embryo (Fig. 1 A,C). Thereafter, Xbra initiated zygotic expression, and the ring-shaped expression was observed at the late gastrula stage (Fig. 1 B,D). Comparison of the expression areas between Xbra and Xdelta1 revealed that both Xbra and Xdelta1 appear to be expressed in the same area. Double in situ hybridization was performed in the st.11.5 embryo to further compare the expression region between Xdelta1 and Xbra. As shown in Fig. $1 \mathrm{E}$ and $\mathrm{F}$, gene expression of Xdelta1 and Xbra was detected in the same region of the st.11.5 embryo (Fig. 1 E,F). The co-expression of Xdelta1 and Xbra suggests that Xdelta1 plays an important role in mesoderm formation. To clarify the role of Xdelta1 in mesoderm formation, morpholino oligo DNA of Xdelta1 (Xdelta1-MO) was directly injected into the lateral side of one blastomere at the 2-cell stage, and morphogenetic movement was observed at the gastrula stage. In contrast to normal gastrulation in control embryos, the Xdelta1-MO-injected embryo showed the gastrulation defect in the injection side (Fig. 2 A,B). The Xdelta1-MO-induced gastrulation defect was completely rescued by co-injection with the active form of Notch (NICD) (Fig. 2C). Whole-mount in situ hybridization showed that Xbra expression was inhibited by Xdelta1-MO, which was rescued by co-injection of NICD (Fig.
$2 \mathrm{D}-\mathrm{F})$. These results indicate that Notch signaling is necessary for mesoderm formation.

\section{XESR5 initiates zygotic expression prior to XESR1 expres- sion}

XESR1 functions as a typical Notch target gene during neurogenesis. To understand the role of Notch target gene in mesoderm formation, gene expression of XESR1 and XESR5 was compared during gastrulation. RT-PCR analysis indicated that gene expression of XESR1 was not detected in the st.10 embryo, while the initial gene expression of XESR5 was recognized from st.10 (Fig. 3A). In order to clarify the initial stage of the gene expression during mesoderm formation, spatiotemporal expression of both genes was examined by whole-mount in situ hybridization. As shown in Fig. 3B, gene expression of XESR5 was observed in the marginal zone of st.10.5 embryo which showed no expression of XESR1. XESR5 expression is known to be activated by Notch signaling in segmentation of the paraxial mesoderm (Jen et al., 1999). To further determine whether XESR5 is the target of Notch signaling in the mesoderm formation, animal caps were isolated from the embryo injected with NICD and Xnr2, and gene expression was examined by RT-PCR analysis. Surprisingly, results show that gene expression of

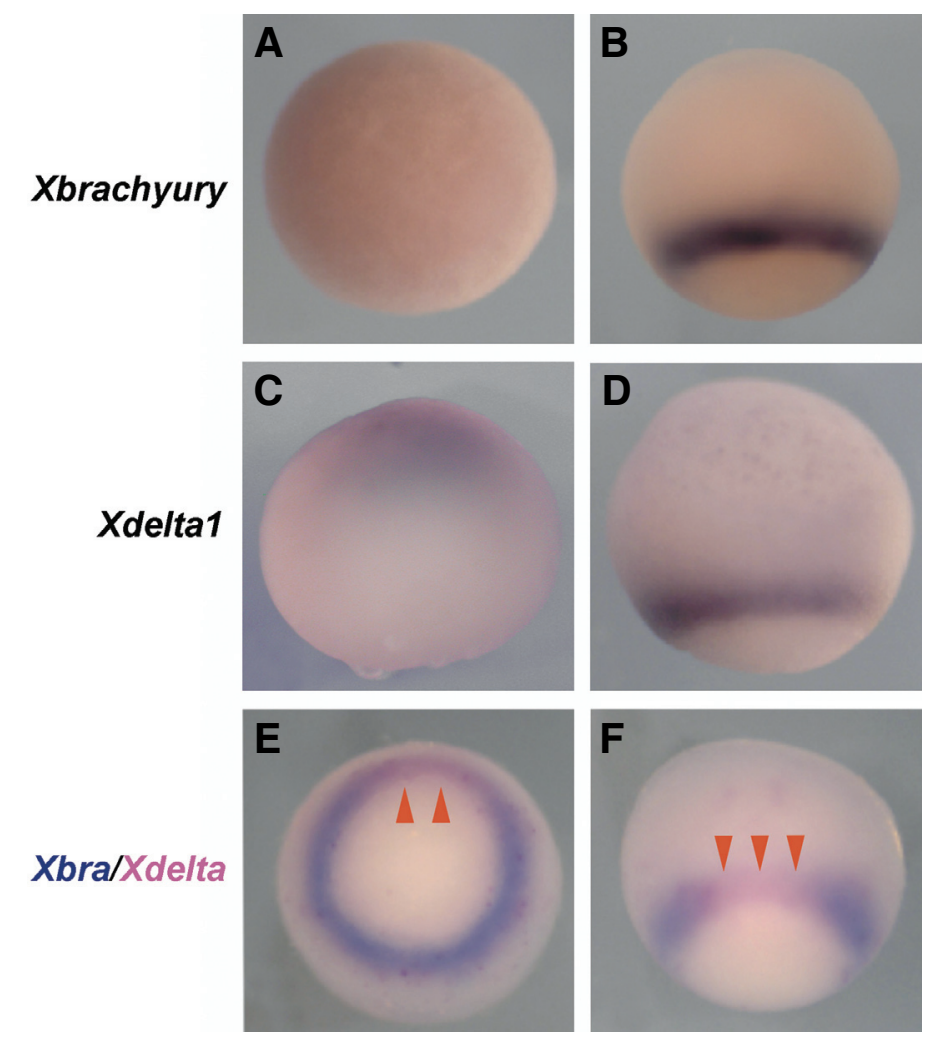

Fig. 1. Comparison of gene expression profiles of $\mathrm{Xbra}$ and $\mathrm{Xdelta1.}$ (A-D) Gene expression of Xbra (A,B) and Xdelta1 (C,D) at st.9 (A,C) and st.11.5 (B,D). All embryos are shown in lateral view with the dorsal side right. Xdelta1 shows the zygotic expression prior to Xbra expression. (E,F) Double in situ hybridization of Xbra (blue) and Xdelta1 (red) in the st.11.5 embryo. (E) Vegetal view with the dorsal side up. (F) Dorsal view with the animal side up. Gene expression of Xbra and Xdelta1 overlapped with each other in the same marginal zone. Xdelta1 expression was recognized in the Xbra-free dorsal area (arrowheads). 

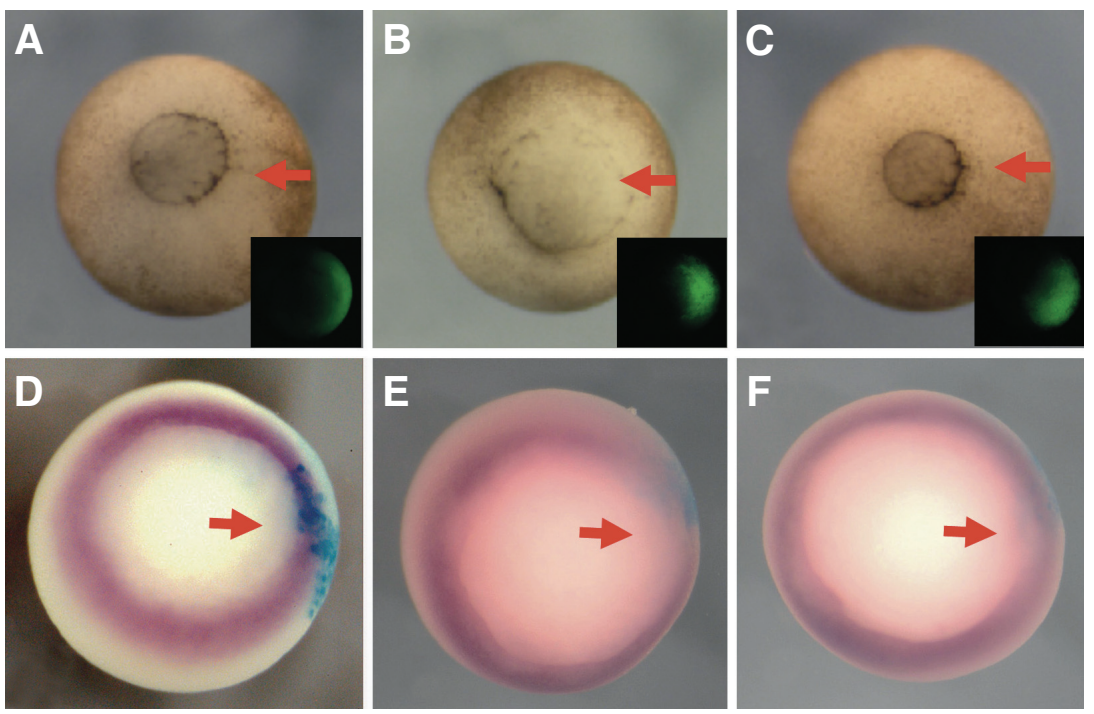

Fig. 2. Effect of Xdelta1-MO on gastrulation and Xbra expression. Xdelta1-MO and tracer mRNAs were injected into the lateral side of one blastomere at the 2-cell stage. Gastrulation (A-C) and Xbra expression (D-F) were examined in the injected embryo at st.12 and st.10.5, respectively. All embryos are shown in vegetal view with the ventral side up, and arrows indicate the injection side. GFP (A-C) and $\beta$-gal (D-F) were used as tracers of the injection side. In contrast to the normal gastrulation of the GFP-injected control embryo (A), Xdelta 1-MO caused the gastrulation defect in the injection side (B), which was completely rescued by co-injection of NICD (C). Xdetla1$M O$ inhibited Xbra expression (E), which was rescued by co-injection of NICD (F). Injection of $\beta$-gal into control embryos showed no effect on Xbra expression (D).
XESR5 was induced not by NICD, but by Xnr2 (Fig.4, lanes 2-5). In contrast, XESR1 expression was induced not by Xnr2 but by NICD (Fig. 4, lanes 2-5). In the animal cap co-injected with Xnr2 and NICD, XESR1 and XESR5 showed moderate levels of expression (Fig. 4, lane 5). These results suggest that the regulatory mechanism of gene expression is different between XESR1 and XESR5 in mesoderm formation.

\section{Antagonistic expression of XESR1 and XESR5}

As shown above, Xnr2-induced XESR5 expression was substantially suppressed in the NICD-injected cap (Fig. 4, lane 5). In contrast, NICD-activated XESR1 expression was suppressed in the Xnr2-expressing cap. These results suggest a possibility that XESR1 and XESR5 antagonistically regulate the gene expression of each other. To test this possibility, we examined the relationship between XESR1 gene expression and XESR5 gene expression by using Xnr2-injected animal cap. Gene expression of XESR5 was induced in the Xnr2-expressing animal cap (Fig. 5, lane 2). However, the Xnr2-induced XESR5 was downregulated by co-injection of XESR1 (Fig. 5, lane 3). In contrast, co-injection of the dominant negative form of XESR1 (DN-XESR1) upregulated the Xnr2-induced XESR5 expression (Fig. 5, lane 4). Gene expression of XESR1 was not detected in the Xnr2-expressing animal cap (Fig. 5, lane 2). Co-injection of XESR5 did not cause the ectopic expression of XESR1 (Fig. 5, lane 5). However, the dominant negative form of XESR5 (DN-XESR5) induced a high expression of the XESR1 gene (Fig. 5, lane 6). These results suggest that XESR1 and XESR5 antagonistically regulate the

\section{Fig. 3. Spatiotemporal expression profile of XESR1 and XESR5.}

(A) Quantitative RT-PCR analysis of XESR1 and XESR5 during early development. Initial gene expression of XESR5 was detected at st. 10 and gradually increased up to st.20, whereas initial gene expression of XESR1 was recognized from st.11. E: unfertilized egg. Histone $\mathrm{H} 4$ was used as the internal marker. -RT: without reverse transcriptase reaction. Numbers on the photograph indicate the Nieuwkoop and Faber's developmental stage. (B) Whole-mount in situ hybridization of XESR1 lleft column) and XESR5 (right column) in the st.10.5 embryo. Upper row shows the lateral view with the dorsal side right, and lower row shows the vegetal view with the ventral side up. gene expression of each other. To confirm this finding, synthesized RNAs for XESR1 or DN-XESR5 were injected into the lateral side of one blastomere at the 2-cell stage, and gene expression of XESR5 or XESR 1 was examined at st.10.5 by whole-mount in situ hybridization. Microinjection of XESR1 suppressed the zygotic expression of XESR5 in the injection side, whereas microinjection of DN-XESR5 induced the ectopic expression of XESR1 in the injection side (Fig. 6). These results demonstrated that XESR1 and XESR5 show antagonistic gene expression in the marginal zone of the gastrula embryo.

\section{Role of XESR1 and XESR5 in Xbra expression}

XESR5 showed the ring-shaped expression in the marginal zone of the st. 10.5 embryo, but XESR1 did not (Fig. 3B). To further

\section{A}

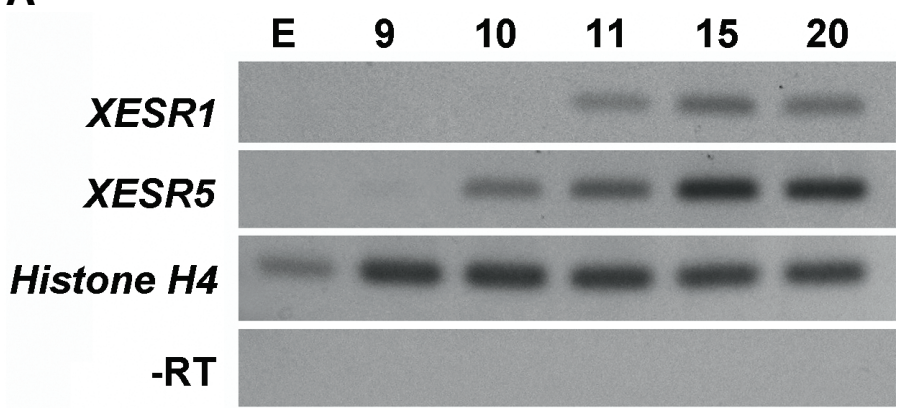

B

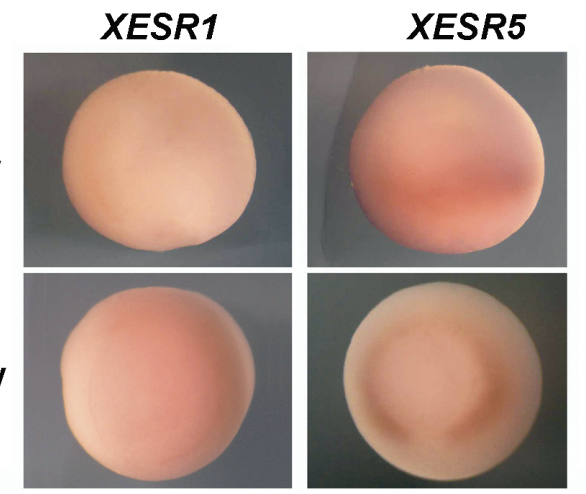



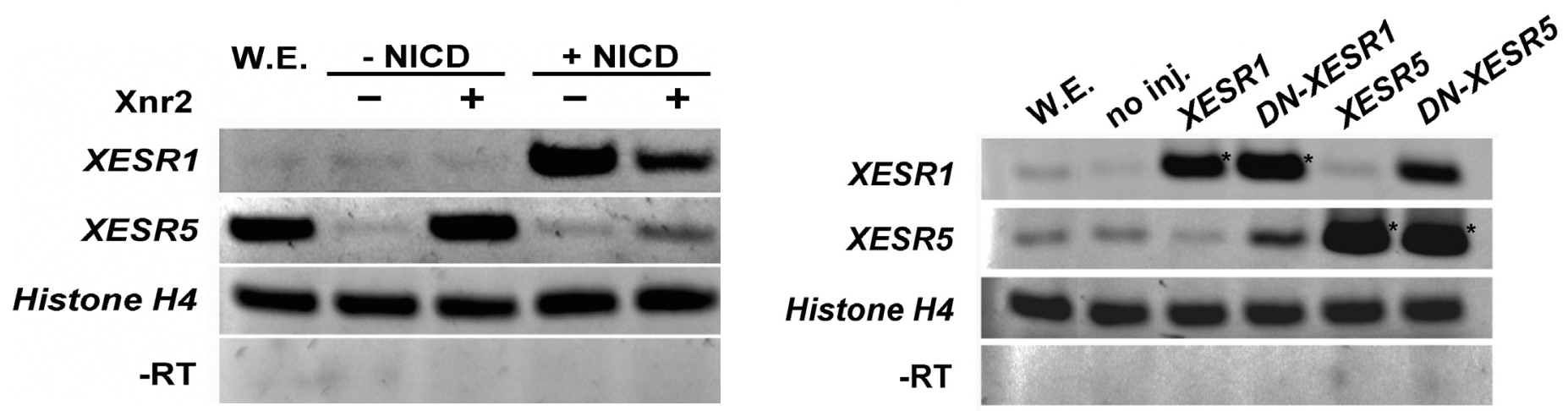

Fig. 4. (Left) Effect of Xnr2 and notch intracellular domain (NICD) on the gene expression of XESR1 and XESR5. Synthesized RNAs of Xnr2 and/or NICD were injected into the animal side of both blastomeres at the 2-cell stage. Animal caps were isolated from the injected embryo at st. 9 and cultured until st.10.5, when gene expression of XESR 1 and XESR5 was examined by quantitative RT-PCR. Histone H4 was used as the internal marker. -RT: without reverse transcriptase reaction. W.E.: whole embryo.

Fig. 5. (Right) Antagonistic gene expression of XESR1 and XESR5. Synthesized RNAs of Xnr2 andXESR1, DN-XESR1, XESR5, or DN-XESR5 were injected into the animal side of both blastomeres at the 2-cell stage. Animal caps isolated from the injected embryo at st. 9 were cultured until st. 10.5 , and gene expression of XESR 1 and XESR5 was examined by quantitative RT-PCR. Large bands marked with asterisk show the total mRNA containing endogenous and exogenous mRNA. Histone H4 was used as the internal marker. -RT: without reverse transcriptase reaction. W. E.: whole embryo. To detect the quantitative difference in XESR5 expression, the number of PCR cycles was reduced to 24 in this experiment.

understand the role of XESR1 and XESR5 in mesoderm formation, wild type or dominant negative form of XESR1 or XESR5 was injected into the lateral side of one blastomere at 2-cell stage, and Xbra expression in the injected embryo was examined at st.10.5 by whole-mount in situ hybridization. Results show that overexpression of XESR1 inhibited the Xbra expression, whereas DN-XESR1 induced the upregulation of the Xbra expression in the injection side (Fig. $7 \mathrm{~A}-\mathrm{C}$ ). In contrast, overexpression of XESR5 upregulated Xbra expression, while DN-XESR5 caused

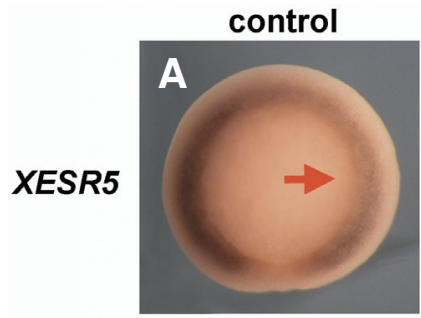

control

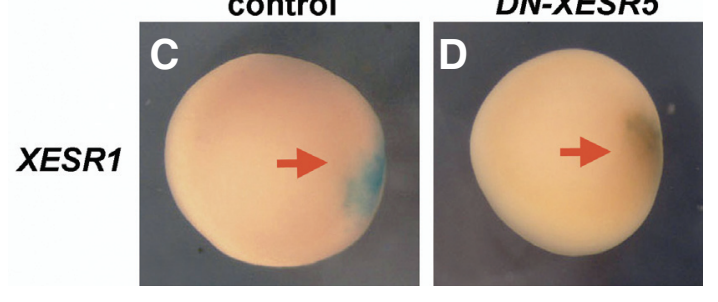

the downregulation of Xbra expression in the injection side (Fig. $7 \mathrm{D}, \mathrm{E})$. These results suggest that XESR1 and XESR5 may function as antagonists in mesoderm formation.

\section{Discussion}

\section{Antagonistic expression of XESR1 and XESR5}

It has been shown that one of the Notch ligands, Xdelta1, is expressed in the marginal zone of early gastrula (Wittenberger et
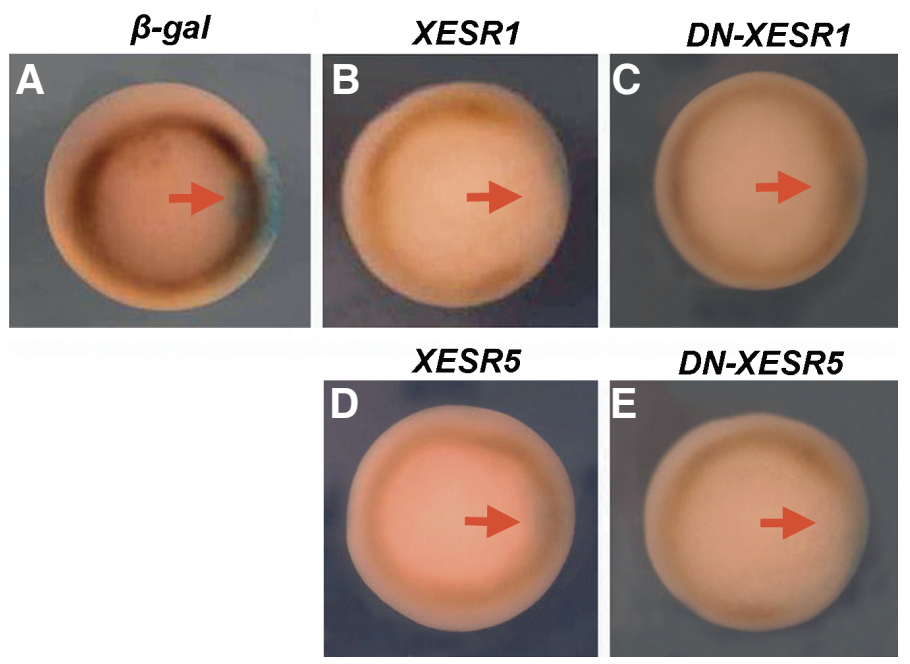

DN-XESR5

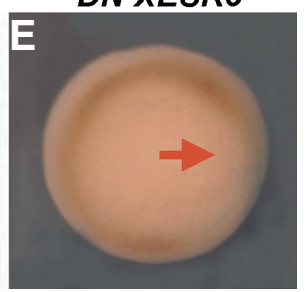

Fig. 6 (Left). Inhibitory transcriptional regulation of XESR1 and XESR5. Synthesized RNAs of $\beta$-gal (A,C), XESR1 and $\beta$-gal (B) or DN-XESR5 and $\beta$-gal (D) were injected into the lateral side of one blastomere at the 2-cell stage, and gene expression of XESR5 (A,B) or XESR1 (C,D) was examined at st. 10.5 by whole-mount in situ hybridization. All embryos are shown in vegetal view with the ventral side up. Arrows indicate the injection side. XESR1 inhibited the gene expression of XESR5 ( $B$, arrow), while DN-XESR5 induced the ectopic expression of XESR1 (D, arrow).

Fig. 7. (Right) Effect of XESR1 and XESR5 on the gene expression of Xbra. Synthesized RNAs of XESR1 (B), DN-XESR1 (C), XESR5 (D) or DNXESR5 (E) were injected into the lateral side of one blastomere at the 2-cell stage together with $\beta$-gal as a lineage tracer, and gene expression of Xbra was examined at st. 10.5 by whole-mount in situ hybridization. Control embryo was injected with $\beta$-gal alone (A). All embryos are shown in vegetal view with the ventral side up. Arrows indicate the injection side. 
al., 1999). However, XESR1, one of the Notch target genes, is not expressed in the early gastrula. The first drastic expression of XESR1 has been reported under the Notch signaling in the primary neurogenesis (Wettstein et al., 1997). In the epidermis of the neurula, XESR6e, another HES family gene, has been shown to be involved in the cell fate decision during cilia cell formation (Deblandre et al., 1999). XESR6e is not expressed in the gastrula embryo, but shows the dotted expression pattern in the epidermis of neurula stage embryo. The present study demonstrates that XESR5 is expressed in the marginal zone of early gastrula embryo (Fig. 3B). During myotome formation, XESR5 controls the segmentation of paraxial mesoderm under the Notch signaling (Jen et al., 1999). However, the present study results demonstrate that gene expression of XESR5 is induced not by the Notch signaling but by Xnr2. Loss- and gain-of-function experiments indicate that XESR1 and XESR5 inhibit the gene expression of each other (Fig. 5,6). The antagonistic regulation of the gene expression is consistent with the negative cross-regulation between hes 5 and hes 6 in chick neurogenesis (Fior and Henrique, 2005). The results are also consistent with those obtained in mouse HES family genes where Hes6 and Hes1 play an antagonistic role, leading to the periodic segmentation (Bae et al., 2000; Gratton et al., 2003). Taken together, it is likely that Xnr2-induced gene expression of XESR5 occurs prior to the activation of Notch signaling, which results in the suppression of XESR1 expression (Fig. 8).

\section{Boundary formation of Xbra expression}

In Xenopus gastrula embryo, the mesoderm formation occurs in the marginal zone, which is visualized by the zygotic expression of Xbra. Mesoderm-inducing factor such as activin and nodalrelated genes induces Xbra expression in a concentration-dependent manner (Gurdon et al., 1994, 1995, 1996). In vitro studies using the dissociated blastula cells indicate that the interpretation

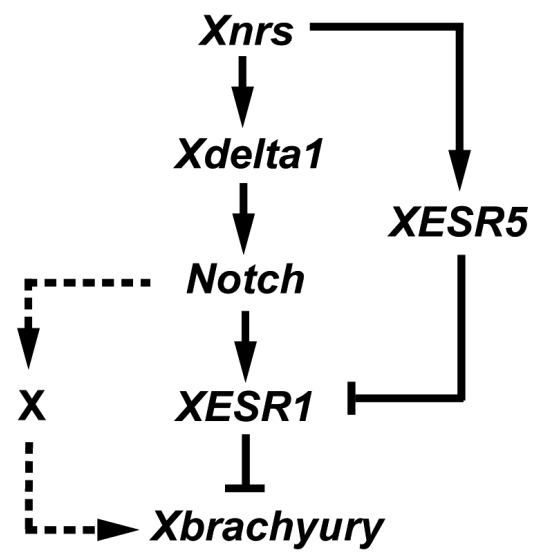

Fig. 8. A dual regulation model showing a hypothetical role of Notch signaling in mesoderm formation. Zygotic expression of Xdelta 1 and XESR5 is induced by mesoderm-inducing factors. Since XESR5 expression initiates prior to activation of Notch, XESR5 is able to produce a competent area for Xbra expression by inhibiting the gene expression of XESR1. Xdelta1-activated XESR1 might play a role to suppress the overexpression of Xbra. Another role of Notch signaling might be to promote Xbra expression by activating a novel target gene $X$. These transcriptional networks could refine the Xbra-expressing area in the Xenopus gastrula embryo. of concentration of activin by cells is dependent upon the concentration of Smad2 in the nucleus (Bourillot et al., 2002). In addition to the concentration-dependent mesoderm induction, the refinement mechanism of Xbra expression has been reported, which requires protein synthesis (Papin and Smith, 2000). Animal cap assay demonstrates that the boundary formation of activininduced Xbra expression requires protein synthesis (Kinoshita et al., 2006). However, the type of proteins that control the boundary formation of Xbra expression remains to be determined. In the present study, DN-XESR1 caused the upregulation of XESR5, which increased Xbra expression (Fig. 5,7). These results suggest that the antagonistic regulation of XESR1 and XESR5 is involved in the boundary formation of Xbra expression.

\section{Dual role of Notch signaling in Xbra expression}

In Xenopus development, the essential role of Notch signaling in primary neurogenesis has been well known (Chitnis et al., 1995). Prior to the neurogenesis, the initial zygotic expression of Xdelta1 occurs in the marginal zone of early gastrula (Wittenberger et al., 1999). Functional analysis of I-Fringe, which is a Notch signal regulator, has indicated that Notch signaling in gastrula embryo is involved in the myogenesis (Wu et al., 1996). In the present study, Xdelta1-MO caused the inhibition of Xbra expression and the gastrulation defect, which was completely rescued by co-injecting with NICD. These results suggest that Notch signaling is required for the mesoderm formation. Since XESR1, a canonical Notch target gene, suppresses Xbra expression (Ito et al., 2007a), one possible role of Notch signaling in gastrula embryo might be to refine the boundary of Xbra expression by antagonistic regulation of XESR1 and XESR5. In many aspects of metazoan development, Notch signaling activates or suppresses various non-canonical target genes (Kopan and llagen, 2009). In fact, a previous report has demonstrated that Notch signaling in Xenopus gastrula embryos regulates the cell competency for the mesoderm inducing factor in $\mathrm{Su}(\mathrm{H})$-independent manner (Abe et al., 2005). Taking together, we can suppose two roles of Notch signaling, one is the inhibiting and another is the activating role in the Xbra expression (Fig. 8). Our previous study using $\mathrm{XSu}(\mathrm{H}) 2-\mathrm{MO}$ has indicated that Notch signaling promotes the Xbra expression by activating a novel target gene (Ito et al., 2007a). A potential candidate for the novel target gene is POU family gene (Ito et al., 2007b); however, further studies are necessary for understanding the activating role of Notch signaling in the mesoderm formation.

\section{Materials and Methods}

\begin{abstract}
Egg and embryos
Xenopus eggs were obtained by injecting human chorionic gonadotropin, gestron (Denka Seiyaku, Japan) into Xenopus laevis female and fertilized with the testis isolated from $X$. laevis male by surgical operation. Embryos were dejellied with 2\% L-cysteine and cultured in $0.1 \mathrm{x}$ MBS (Modified Barth Saline). The developmental stages of embryos were determined according to the normal table of $X$. laevis (Nieuwkoop and Faber, 1967). Animal caps were excised from the blastula embryo at st. 8 and cultured in $1 \times$ MBS containing $100 \mathrm{mg} / \mathrm{L}$ kanamycin until st.10.5, when gene expression in the explants was examined.
\end{abstract}

\section{Constructs and morpholino antisense oligonucleotides}

Dominant negative forms of XESR1 (DN-XESR1) and XESR5 (DN- 
XESR5) were constructed according to a previous report (Ito et al. 2007b). In these constructs, the carboxyl-terminal WRPW motif (Fisher et al., 1996, Giebel and Campos-Ortega, 1997) was deleted by PCR on a template of XESR-1/pCS2+ or XESR-5/pCS2+, and the PCR product was

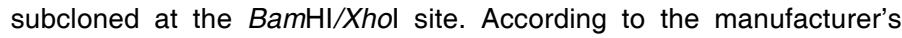
instructions (Gene Tools), morpholino antisense oligonucleotides (MO) for XDelta1 was designed as follows:

5'-GCGCTGCTGTCCCATGTTGTCTGAT-3'.

\section{RNA synthesis and microinjection}

All capped mRNAs were synthesized from linearized plasmids using SP6 RNA polymerase (Epicentre Technology). Capped mRNA was made using the mCAP RNA synthesis kit (Gibco BRL) according to the manufacturer's instructions. NICD RNA was made from NICD/pCS2+ (Chitnis et al., 1995), and $\beta$-galactosidase RNA was produced from pCMV-SPORT $\beta$-gal (Stratagene). Fertilization, culture, and microinjection were performed as described previously (Moon and Christian, 1989, Asashima et al., 1990). One blastomere of a 2-cell-stage embryo was injected with $5 \mathrm{nl}$ solution containing $500 \mathrm{pg}$ mRNA or $30 \mathrm{ng}$ morpholino oligo DNA.

\section{RT-PCR analysis}

Total RNA was extracted from embryos or animal caps using the Isogen solution (Nippongene). Oligo (dT)-primed first strand cDNA was prepared from $0.5 \mathrm{ng}$ of total RNA using Reverscript1 (Wako, Japan). Each PCR was performed using this CDNA as a template. The RT-PCR conditions were as follows: $95^{\circ} \mathrm{C}$ for $2 \mathrm{~min}, 55^{\circ} \mathrm{C}$ for $2 \mathrm{~min}$ and 26 cycles of $72^{\circ} \mathrm{C} 1 \mathrm{~min}, 95^{\circ} \mathrm{C} 30 \mathrm{sec}$ and $55^{\circ} \mathrm{C} 30 \mathrm{sec}$. The primer sequences used are as follows:

XESR1

$\begin{array}{ll}\text { Upstream } & \text { 5'-ACAAGCAGGAACCCAATGTCA-3' } \\ \text { Downstream } & \text { 5'-GCCAGAGCTGATTGTTTGGAG-3' }\end{array}$

XESR5

$$
\begin{array}{ll}
\text { Upstream } & \text { 5'-TTCATCAGCGAGATCAGTCC-3' } \\
\text { Downstream } & \text { 5'-TACAATGGCGGCTGTTCATG-3' }
\end{array}
$$

Histone $\mathrm{H} 4$

Upstream 5'-CGGGATAACATTCAGGGTATCACT-3'

Downstream 5'-ATCCATGGCGGTAACTGTCTTCCT-3'

\section{Whole-mount in situ hybridization analysis}

Whole-mount in situ hybridization was performed according to the improved method of Shain and Zuber (1996). Hybridized probes were visualized according to the Röche Diagnostics DIG protocol, with a minor alternation that $0.45 \mu \mathrm{l} \mathrm{NBT}(75 \mathrm{mg} / \mathrm{ml}$ in dimethyl formamide) and $3.5 \mu \mathrm{l}$ $\mathrm{BCIP}(50 \mathrm{mg} / \mathrm{ml}$ in dimethyl formamide) were added to $1 \mathrm{ml}$ AP buffer (100 $\mathrm{mM}$ Tris- $\mathrm{HCl}$ (pH 9.5), $100 \mathrm{mM} \mathrm{NaCl}, 50 \mathrm{mM} \mathrm{MgSO}$, 0.1\% Tween 20, 2.5 $\mathrm{mM}$ levamisole). For double in situ hybridization, the second probe was labeled with FITC-conjugated UTP instead of DIG-UTP, and the probe was visualized with Magenta (Röche Diagnostics) for AP substrate. The antisense RNA probes of Xbra, Xdelta1, XESR1, and XESR5 were prepared by linearizing pCS2+ vector with $E c o R I$ and transcribed with T7 RNA polymerase.

\section{Acknowledgements}

We thank Dr. C. Kintner for providing NICD and Dr. M. Klymkowsky for pCS2mtUGP. This work was supported by a Grant-in-Aid from the Ministry of Education, Science, Sports and Culture of Japan.

\section{References}

ABE, T., FURUE, M., KONDOW, A., MATSUZAKI, K., ASASHIMA, M. (2005). Notch signaling modulates the nuclear localization of carboxy-terminal-phosphorylated smad2 and controls the competence of ectodermal cells for activin A. Mech Dev 122: 671-680.
APELQVIST, A., LI, H., SOMMER, L., BEATUS, P., ANDERSON, D. J., HONJO, T., HRABE DE ANGELIS, M., LENDAHL, U., EDLUND, H. (1999). Notch signalling controls pancreatic cell differentiation. Nature 400: 877-881.

ARTAVANIS-TSAKONAS, S., RAND, M. D., LAKE, R. J. (1999). Notch signaling cell fate control and signal integration in development. Science 284: 770-776.

ASASHIMA, M., NAKANO, H., SHIMADA, K., ISHII, K., SHIBAI, H. and UENO, N (1990). Mesodermal induction early amphibian embryos by activin A (erythroid differentiation factor). Roux's Arch. Dev. Biol. 198: 859-875.

BAE, S., BESSHO, Y., HOJO, M., KAGEYAMA, R. (2000). The bHLH gene Hes6, an inhibitor of Hes1, promotes neuronal differentiation. Development 127 2933-2943.

BEREZOVSKA, O., JACK, C., MCLEAN, P., ASTER, J. C., HICKS, C., XIA, W., WOLFE, M. S., WEINMASTER, G., SELKOE, D. J., HYMAN, B. T. (2000). Rapid Notch1 nuclear translocation after ligand binding depends on presenilin-associated gamma-secretase activity. Ann N Y Acad Sci 920: 223-226.

BOURILLOT, P. Y., GARRETT, N., GURDON, J. B. (2002). A changing morphogen gradient is interpreted by continuous transduction flow. Development 129 2167-2180.

CHITNIS, A., HENRIQUE, D., LEWIS, J., ISH-HOROWICZ, D., KINTNER, C (1995). Primary neurogenesis in Xenopus embryos regulated by a homologue of the Drosophila neurogenic gene Delta. Nature 375: 761-766.

DEBLANDRE, G.A., WETTSTEL,D.A., KOYANO-NAKAGAWA, N., KINTNER, C (1999). A two-step mechanism generates the spacing pattern of the ciliated cells in the skin of Xenopus embryos. Development 126: 4715-4728.

EBINU, J. O., YANKNER, B. A. (2002). A RIP tide in neuronal signal transduction. Neuron 34: 499-502

FIOR, R., HENRIQUE, D. (2005). A novel hes5/hes6 circuitry of negative regulation controls Notch activity during neurogenesis. Dev Biol 281: 318-333.

FISHER, A.L., OHSAKO, S. and CAUDY, M. (1996). The WRPW Motif of the HairyRelated Basic Helix-Loop-Helix Repressor Proteins Acts as a 4-Amino-Acid Transcription Repression and Protein-Protein Interaction Domain. Mol. Cell Biol. 16: 2670-2677.

FURUKAWA, T., MARUYAMA, S., KAWAICHI, M., HONJO, T. (1992). The Drosophila homolog of the immunoglobulin recombination signal-binding protein regulates peripheral nervous system development. Cell 69: 1191-1197.

GIEBEL, B. and CAMPOS-ORTEGA, J.A. (1997). Functional dissection of the Drosophila enhancer of split protein, a suppressor of neurogenesis. Proc. Natl. Acad. Sci. U.S.A. 94: 6250-6254

GRATTON, M. O., TORBAN, E., JASMIN, S. B., THERIAULT, F. M., GERMAN, M S., STIFANI, S. (2003). Hes6 promotes cortical neurogenesis and inhibits Hes1 transcription repression activity by multiple mechanisms. Mol Cell Biol23: 6922 6935.

GURDON, J. B., HARGER, P., MITCHELL, A., LEMAIRE, P. (1994). Activin signalling and response to a morphogen gradient. Nature 371: 487-492.

GURDON, J. B., MITCHELL, A., MAHONY, D. (1995). Direct and continuous assessment by cells of their position in a morphogen gradient. Nature 376: 520 521.

GURDON, J. B., MITCHELL, A., RYAN, K. (1996). An experimental system for analyzing response to a morphogen gradient. Proc Natl Acad Sci USA 93: 9334 9338.

HAN, H., TANIGAKI, K., YAMAMOTO, N., KURODA, K., YOSHIMOTO, M. NAKAHATA, T., IKUTA, K., HONJO, T. (2002). Inducible gene knockout of transcription factor recombination signal binding protein-J reveals its essential role in $\mathrm{T}$ versus $\mathrm{B}$ lineage decision. Int Immunol 14: 637-645.

HOJO, M., OHTSUKA, T., HASHIMOTO, N., GRADWOHL, G., GUILLEMOT, F., KAGEYAMA, R. (2000). Glial cell fate specification modulated by the bHLH gene Hes5 in mouse retina. Development 127: 2515-2522.

ISO, T., SARTORELLI, V., CHUNG, G., SHICHINOHE, T., KEDES, L., HAMAMORI Y. (2001). HERP, a new primary target of Notch regulated by ligand binding. Mol Cell Biol 21: 6071-6079.

ITO, M., KATADA, T., MIYATANI, S., KINOSHITA, T. (2007a). XSu(H)2 is an essential factor for gene expression and morphogenesis of the Xenopus gastrula embryo. Int J Dev Biol 51: 27-36.

ITO, M., NISHITANI, E., KINOSHITA, T. (2007b). Xenopus Suppressor of Hairless 2 is involved in the cell fate decision during gastrulation through the transcrip- 
tional regulation of Xoct25/91. Biochem Biophys Res Commun 353: 644-649.

JARRIAULT, S., BROU, C., LOGEAT, F., SCHROETER, E. H., KOPAN, R., ISRAEL, A. (1995). Signalling downstream of activated mammalian Notch. Nature 377: 355-358.

JEN, W. C., GAWANTKA, V., POLLET, N., NIEHRS, C., KINTNER, C. (1999). Periodic repression of Notch pathway genes governs the segmentation of Xenopus embryos. Genes Dev 13: 1486-1499.

KARISTROM, H., BERGMAN, A., LENDAHL, U., NASLUND, J., LUNDKVIST, J. (2002). A sensitive and quantitative assay for measuring cleavage of presenilin substrates. J Biol Chem 277: 6763-6766.

KINOSHITA, T., JULLIEN, J., GURDON, J. B. (2006). Two-dimensional morphogen gradient in Xenopus: boundary formation and real-time transduction response. Dev Dyn 235: 3189-3198.

KIYOTA, T., JONO, H., KURIYAMA, S., HASEGAWA, K., MIYATANI, S., KINOSHITA, T. (2001). X-Serrate-1 is involved in primary neurogenesis in Xenopus laevis in a complementary manner with X-Delta-1. Dev Genes Evol 211: 367-376.

KOPAN, R., ILAGAN, M.X.G. (2009). The canonical Notch signaling pathway: unfolding the activation mechanism. Cell 137: 216-233.

KOYANO-NAKAGAWA, N., WETTSTEIN, D., KINTNER, C. (1999). Activation of Xenopus genes required for lateral inhibition and neuronal differentiation during primary neurogenesis. Mol Cell Neurosci 14: 327-339.

MAIER, M. M., GESSLER, M. (2000). Comparative analysis of the human and mouse Hey1 promoter: Hey genes are new Notch target genes. Biochem Biophys Res Commun 275: 652-660.
MOON, R.T. and CHRISTIAN, J.L. (1989). Microinjection and expression of synthetic mRNAs in Xenopus embryos. Tech. J. Methods Cell Mol. Biol. 1: 76-89.

MUMM, J. S., KOPAN, R. (2000). Notch signaling: from the outside in. Dev Biol228: 151-165.

NAKAGAWA, O., MCFADDEN, D. G., NAKAGAWA, M., YANAGISAWA, H., HU, T., SRIVASTAVA, D., OLSON, E. N. (2000). Members of the HRT family of basic helix-loop-helix proteins act as transcriptional repressors downstream of Notch signaling. Proc Natl Acad Sci USA 97: 13655-13660.

NIEUWKOOP, P. D., FABER, J. (1967). Normal Table of Xenopus laevis Daudin. North-Holland, Amsterdam. 2nd ed. pp. 1-252.

PAPIN, C., SMITH, J. C. (2000). Gradual refinement of activin-induced thresholds requires protein synthesis. Dev Biol 217: 166-172.

SHAIN, D. H., ZUBER, M. X. (1996). Sodium dodecyl sulfate (SDS)-based wholemount in situ hybridization of Xenopus laevis embryos. J Biochem Biophys Methods 31: 185-188.

WETTSTEIN, D. A., TURNER, D. L., KINTNER, C. (1997). The Xenopus homolog of Drosophila Suppressor of Hairless mediates Notch signaling during primary neurogenesis. Development 124: 693-702.

WITTENBERGER, T., STEINBACH, O. C., AUTHALER, A., KOPAN, R., RUPP, R. A. (1999). MyoD stimulates delta-1 transcription and triggers notch signaling in the Xenopus gastrula. EMBO J 18: 1915-1922.

WU, J. Y., WEN, L., ZHANG, W. J., RAO, Y. (1996). The secreted product of Xenopus gene lunatic Fringe, a vertebrate signaling molecule. Science 273: 355-358. 


\section{Further Related Reading, published previously in the Int. J. Dev. Biol.}

See our Special Issue The Spemann-Mangold Organizer edited by Eddy DeRobertis and Juan Aréchaga at: http://www.ijdb.ehu.es/web/contents.php?vol=45\&issue=1

Retinoid signalling is required for information transfer from mesoderm to neuroectoderm during gastrulation Ferran Lloret-Vilaspasa, Hans J. Jansen, Koen de Roos, Rosh A.S. Chandraratna, Maija H. Zile, Claudio D. Stern and Antony J. Durston Int. J. Dev. Biol. (2010) 54: 599-608

Zygotic VegT is required for Xenopus paraxial mesoderm formation and is regulated by Nodal signaling and Eomesodermin Masakazu Fukuda, Shuji Takahashi, Yoshikazu Haramoto, Yasuko Onuma, Yeon-Jin Kim, Chang-Yeol Yeo, Shoichi Ishiura and Makoto Asashima

Int. J. Dev. Biol. (2010) 54: 81-92

Dynamic expression pattern of distinct genes in the presomitic and somitic mesoderm during Xenopus development Audrey Bourdelas, Hong-Yan Li, Clémence Carron and De-Li Shi

Int. J. Dev. Biol. (2009) 53: 1075-1079

Lef1 plays a role in patterning the mesoderm and ectoderm in Xenopus tropicalis Giulietta Roël, Yoony Y.J. Gent, Josi Peterson-Maduro, Fons J. Verbeek and Olivier Destrée Int. J. Dev. Biol. (2009) 53: 81-89

$\mathrm{XSu}(\mathrm{H}) 2$ is an essential factor for gene expression and morphogenesis of the Xenopus gastrula embryo Motoaki Ito, Tomohisa Katada, Seiji Miyatani and Tsutomu Kinoshita Int. J. Dev. Biol. (2007) 51: 27-36

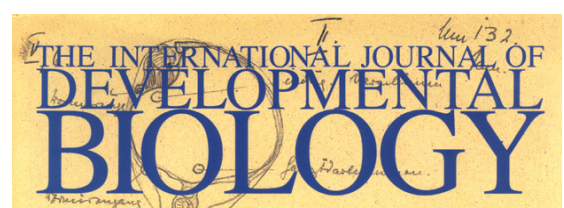

Volume 45 NO. 1

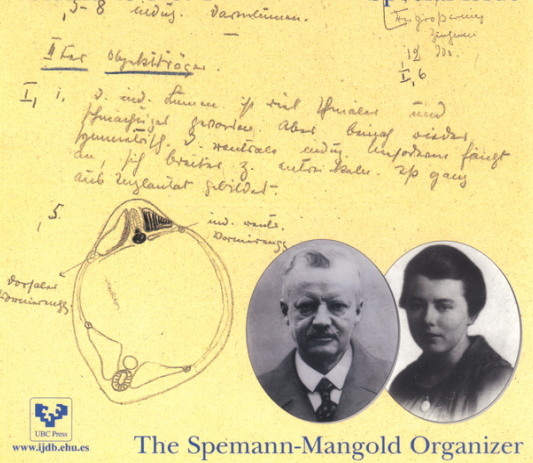

5 yr ISI Impact Factor $(2008)=3.271$
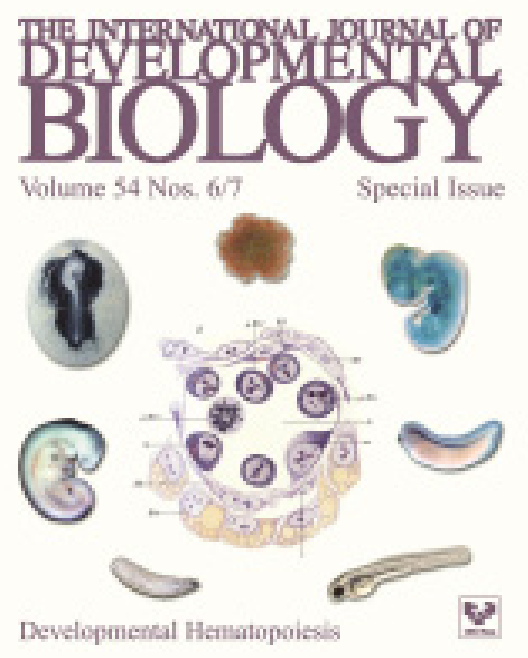

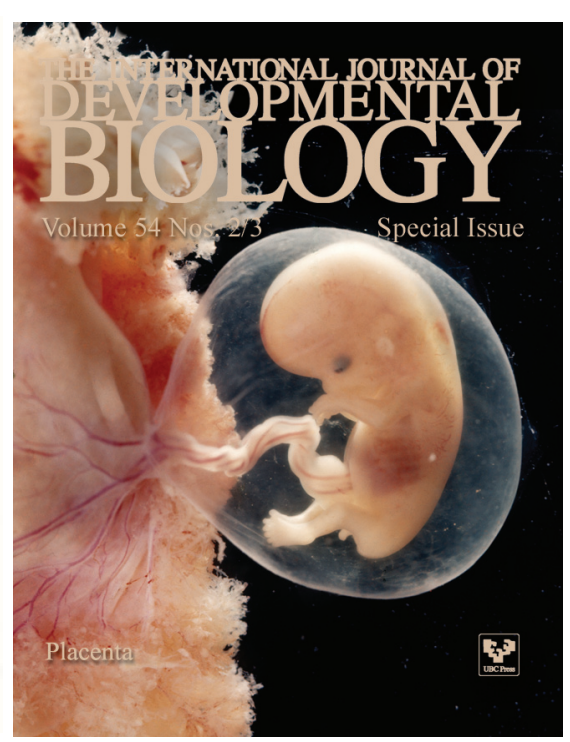

